\title{
Variabilidade genética de Colletotrichum guaranicola usando marcadores AFLP
}

\author{
Jânia Lilia da Silva BENTES ${ }^{1}$, Pedro Queiroz COSTA NETO² \\ RESUMO \\ Foi detectada a variabilidade genética de vinte isolados de Colletotrichum guaranicola (Albuq.) provenientes de diferentes \\ localidades produtoras de guaraná no Amazonas, utilizando-se marcadores moleculares AFLP. Foi possível separar os isolados \\ em dois grupos. O coeficiente de variação genética entre os isolados foi de 0,0216 e a similaridade genética foi de 94,95\%, \\ confirmando que os isolados pertencem à mesma espécie, no entanto, foi observada variabilidade intra-específica.
}

PALAVRAS-CHAVE: Antracnose, guaranazeiro, marcador molecular

\section{Variability of Colletotrichum guaranicola using AFLP markers}

\section{ABSTRACT}

The genetic variability of twenty Colletotrichum guaranicola (Albuq.) isolates from different fields of guarana in Amazonas, was studied using molecular AFLP markers. The isolates were separated into two groups. The genetic variability coefficient was 0.0216 and the genetic similarity was $94.5 \%$, confirming that the isolates belongs to the same species, however, an intraspecific variability was observed.

KEYWORDS: Anthracnose, guaranazeiro, molecular marker.

1 Universidade Federal do Amazonas. jlbentes@ufam.edu.br

2 Universidade Federal do Amazonas. senaneto16@ufam.edu.br 


\section{INTRODUÇÃO}

O Brasil é o único produtor, em termos comerciais, de guaraná (Paullinia cupana var. sorbilis (Mart.) Ducke) do mundo. Estima-se que pelo menos $70 \%$ da produçáo nacional sejam utilizadas pelos fabricantes de refrigerantes, enquanto o restante é comercializado na forma de xarope, bastão, pó, extrato e outras. Em 2008, o Amazonas produziu 751 toneladas de sementes secas de guaraná em 7.815 ha, com um rendimento médio de $96 \mathrm{~kg} \mathrm{ha}^{-1}$ (IBGE 2008). Esta produção é baixa quando comparada com a obtida pelo estado da Bahia que, no mesmo ano, produziu 2.070 toneladas de sementes secas, em uma área de 6.512 ha, tendo um rendimento médio de $317 \mathrm{~kg} \mathrm{ha}^{-1}$. (IBGE 2008). De acordo com Tavares et al. (2005) os clones lançados pela EMBRAPA produzem pelo menos $400 \mathrm{~kg} \mathrm{ha}^{-1}$ ano $^{-1}$ de sementes secas.

Um dos fatores limitantes da produção e expansão da guaranicultura no Amazonas é a antracnose, causada pelo fungo Colletotrichum guaranicola Albuq., considerada a doença mais importante da cultura. O gênero Colletotrichum notoriamente apresenta uma grande variação morfológica, o que reflete a ampla variabilidade genética que ocorre entre e dentro das espécies deste gênero (Sutton 1992).

Estudos indicam que C. guaranicola possui uma ampla base genética (Duarte et al. 1995; Véras et al. 1997; Bentes e Gasparotto 1999), o que pode ter implicação na durabilidade da resistência de clones de guaranazeiro em campo, devido à seleção de variantes do fungo capazes de suplantar a resistência da hospedeira. Duarte et al. (1995) estudaram características morfológicas de oito isolados de C. guaranicola e observaram variação no fenótipo do fungo. Verás et al. (1997) avaliaram a variabilidade morfo-fisiológica de C. guaranicola em diferentes substratos, tendo observado uma grande variabilidade fenotípica entre os isolados. Bentes e Gasparotto (1999) avaliaram a virulência de três isolados de C. guaranicola em sete clones de guaranazeiro, e observaram variação na virulência dos isolados em cada hospedeira testada.

A técnica de AFLP (Amplified Fragment Length Polymorphism) (Vós et al. 1995) foi utilizada para análises moleculares em diversos microrganismos fitopatogênicos (O'Neill et al. 1997; Talhinhas et al. 2002; Peres et al. 2003; Dini-Andreote et al. 2009) permitindo a análise de um grande número de locos por reaçáo com reprodutibilidade dos resultados (Ferreira e Grattapaglia 1996) e pode ser aplicada também a estudos de segregação de genes, visando determinar as bases genéticas e moleculares de fenômenos biológicos em fungos fitopatogênicos, virulência e em estudos taxonômicos (O’ Neill et al. 1997; Silva-Mann et al. 2005; Rodrigues 2010).

Devido ao potencial da guaranicultura no Amazonas e devido às limitaçóes impostas a esta cultura pela ocorrência da antracnose na regiâo, foi avaliada a diversidade genética de isolados de C. guaranicola usando marcadores AFLP com o intuito de fornecer subsídios para o manejo da doença e melhoramento da cultura, baseado no conhecimento da variabilidade do patógeno.

\section{MATERIAL E MÉTODOS}

\section{Isolados do fungo e morfologia}

Os isolados utilizados foram obtidos a partir de plantas naturalmente infectadas em cultivos de guaranazeiro nos municípios de Manaus, Maués, Presidente Figueiredo e Iranduba, no Amazonas. As amostras das folhas apresentaram sintomas típicos da doença, estas foram coletadas e levadas ao laboratório para o isolamento do patógeno, dando-se preferência às folhas com lesōes pequenas, em fase inicial de desenvolvimento. Com o intuito de obter isolados com diversidade genética, dentro de um mesmo campo de cultivo, foram retirados fragmentos de cada lesão de uma mesma folha, para isolamento do fungo. Uma lesão surge a partir de um único esporo, e um esporo pode ser geneticamente distinto dos outros. Os fragmentos selecionados foram submetidos à desinfestação em álcool $70 \%$, hipoclorito de sódio $2 \%$, e lavagens em água destilada autoclavada. $\mathrm{O}$ isolamento foi feito em meio de cultura BDA (batata-dextrose-ágar). As placas foram incubadas à temperatura de $27^{\circ} \mathrm{C}$ durante $24-48$ horas. Após este período, as hifas surgidas a partir dos fragmentos de folha foram repicadas para novas placas contendo o mesmo meio de cultura utilizado para o isolamento das colônias. Estas novas placas foram incubadas em temperatura ambiente (28 $\left.{ }^{\circ} \mathrm{C}\right)$ e expostas à luz fluorescente contínua durante dez dias, visando à esporulação do fungo. Após a obtenção da cultura pura, os isolados foram repicados para BDA em tubos de ensaio, e estocados em incubadora com temperatura de 18 ${ }^{\circ} \mathrm{C}$ sem iluminação.

Para a confirmação da espécie dos fungos isolados foi realizada uma avaliaçấo morfométrica dos conídios. Para isso, foram preparadas lâminas para microscopia e os conídios foram medidos ao microscópio ótico Olympus CX40 (Japão), sob objetiva de 40X, onde foram tomadas as medidas de comprimento e largura dos conídios, usando-se uma ocular micrométrica. Foram medidos 100 conídios de cada isolado e os dados obtidos foram comparados com os descritos na literatura (Albuquerque 1961; Sutton 1980; Bentes e Barreto 2004).

\section{Genotipagem com marcadores AFLP}

A purificação do DNA genômico foi feita a partir de culturas monospóricas de vinte isolados do patógeno, cultivados em $200 \mathrm{~mL}$ em BD (batata-dextrose), sob agitação contínua a $120 \mathrm{rpm}$, durante cinco dias a $26^{\circ} \mathrm{C}$. O micélio foi coletado por filtração à vácuo, utilizando-se filtro (Milipore, Estados Unidos da América) 0,45 $\mu \mathrm{m}$, em câmara de fluxo 
laminar. O DNA foi extraído pelo método fenol/clorofórmio descrito por Raeder e Broda (1985) com adaptaçôes, onde a maceração do micélio do fungo foi feita em tampão CTAB 2\% (Tris 2,42 g; $\mathrm{NaCl}$ 8,2 g; EDTA 0,74 g; Água Mili-Q $100 \mathrm{~mL}$ ) e com sílica (dióxido de silício, partículas de 10-20 nm, SigmaAldrich, Estados Unidos da América). A quantificação do DNA obtido foi feita em gel de agarose $0,8 \%$, com marcador de $50 \mathrm{ng}$ e $100 \mathrm{ng}$ (105ng $\mu \mathrm{L}^{-1}$, Jena Bioscience, Alemanha)

As análises de AFLP foram realizadas de acordo com o método descrito por Vos et al. (1995). Alíquotas de $10 \mu \mathrm{L}$ de DNA genômico (50-250 $\mathrm{ng} \mu \mathrm{L}^{-1}$ ) foram digeridas com as enzimas EcoRI (Invitrogen, Sáo Paulo) e MseI (NEB, Sáo Paulo) a $37^{\circ} \mathrm{C}$ durante três horas e aquecidas a $70^{\circ} \mathrm{C}$ durante 15 minutos para a inativaçáo das enzimas. Os fragmentos de DNA foram ligados aos adaptadores EcoRI R (5'AAT TGG TAC GCA GTC TAC 3'); EcoRI F (5' CTC GTA GAC TGC GTA CC 3') e MseI R (5' TAC TCA GGA CTC AT 3'); MseI F (5' GAC GAT GAG TCC TGA G 3') (Invitrogen, São Paulo), em temperatura de $23^{\circ} \mathrm{C}$ durante três horas. Após a reação de ligação, os fragmentos foram pré-amplificados em 26 ciclos de PCR (Polymerase Chain Reaction), com temperaturas de $94^{\circ} \mathrm{C}$ por 60 segundos, $56^{\circ} \mathrm{C}$ por 60 segundos e $72^{\circ} \mathrm{C}$ por 60 segundos, em termociclador (Eppendorf, Alemanha), utilizando dois conjuntos de primers EcoRI + A e MseI + C; $E c o$ RI + T e MseI + C. Após a amplificação seletiva as amostras foram diluídas com $80 \mu \mathrm{L}$ de água.

Para amplificação seletiva dos fragmentos de DNA foram utilizados dois nucleotídeos seletivos em três combinaçôes diferentes de primers: $E c o \mathrm{RI}+\mathrm{AG}, E c o \mathrm{RI}+\mathrm{AT}$, e $E c o \mathrm{RI}+\mathrm{TA}$. A efetividade de cada um destes foi averiguada em combinaçăo com o primer MseI + C. Uma alíquota de $3 \mu \mathrm{L}$ de DNA préamplificadas de cada amostra foram submetidos à amplificação seletiva utilizando 12 ciclos de PCR com programa: $94^{\circ} \mathrm{C}$ por 30 segundos; $65^{\circ} \mathrm{C}$ por 30 segundos; $72^{\circ} \mathrm{C}$ por um minuto, seguidos de 23 ciclos de $94^{\circ} \mathrm{C}$ por 30 segundos; $56^{\circ} \mathrm{C}$ por 30 segundos e $72{ }^{\circ} \mathrm{C}$ por um minuto. De cada amostra, 15 $\mu \mathrm{L}$ dos produtos da PCR foram separados por eletroforese em gel de poliacrilamida $6 \%$ contendo uréia $7,5 \mathrm{M}$. A corrida foi realizada em equipamento Sequi-Gen GT (BIO-RAD', Estados Unidos da América), durante quatro horas a $80 \mathrm{~W}$ e $3.000 \mathrm{~V}$, com temperatura de $50{ }^{\circ} \mathrm{C}$. A revelação do gel foi feita com nitrato de prata (Creste et al. 2001).

\section{ANÁLISE DE DADOS}

Para cada amostra no gel foi quantificada a presença de bandas com massa molecular entre 50 e 300 pb. A freqüência de bandas foi submetida à análise pelo programa Genes (Cruz 2006). A similaridade genética entre os genótipos foi estimada usando-se o coeficiente de Jaccard (Jaccard 1901). A matriz de similaridade foi analisada pelo método de agrupamento UPGMA (Unweightes Pair-group Method with
Arithmetic Average) (Sneath e Sokal 1973). A consistência das ramificaçóes do dendrograma foi verificada por meio da amostragem repetitiva de dados (Bootstraping), com 1.000 repetiçóes, utilizando o programa POPGEN versão 1.31 (Yeh et al. 1999). A correlação cofenética foi analisada pelo teste de Mantel (Mantel 1967).

\section{RESULTADOS E DISCUSSÃO}

Foram obtidos vinte isolados do fungo C. guaranicola. Os isolados EM1, EM2, EM4, EM6, EM7, EM8, e EM9 foram provenientes do campo experimental da EMBRAPA Amazônia Ocidental, Manaus-AM, os PF11, PF12, PF13, PF17, PF20, PF22, PF23, e PF24 de Presidente Figueiredo-AM, os isolados IRB25 e IRB27 de Iranduba-AM, o isolado MU28 de MauésAM e os isolados MF218 e MF418 da fazenda experimental da Universidade Federal do Amazonas, Manaus-AM.

Os dados morfométricos dos conídios variaram 10,5 $15,5 \times 3,0-4,5 \mu \mathrm{m}$, de acordo com a descriçáo originalmente feita por Albuquerque (1961) e revisada por Bentes e Barreto (2004), de C. guaranicola. De acordo com Sutton (1992) a identificação de espécies do gênero Colletotrichum é baseada em características morfológicas do fungo, podendo ser utilizada gama de hospedeiras.

A definição de espécies deste gênero é difícil devido à ampla variação das características morfológicas, sendo estas delimitadas usando-se poucos caracteres como tamanho e forma de conídios e apressórios e características das colônias, como textura e coloração. A grande plasticidade morfológica é um reflexo da grande variabilidade genética que ocorre neste gênero, além da forte influência do ambiente em alguns caracteres como a formaçáo de setas e produçáo de conídios (Menezes 2002). Vale ressaltar que estudos relacionados com especificidade fisiológica em uma gama de plantas hospedeiras ainda são bastante importantes para a descrição das espécies (Sutton 1992).

Para C. guaranicola alguns estudos referentes aos aspectos morfológicos já foram realizados (Duarte et al. 1995; Verás et al. 1997; Bentes e Gasparotto 1999) indicando uma ampla variabilidade entre isolados do fungo.

O estudo desta variabilidade genética usando marcadores AFLP em isolados de C. guaranicola, apresentou 97 bandas polimórficas, sendo 57 amplificadas com o primer EcoRI + AG e 40 amplificadas com o primer EcoRI + AT, em combinação com o primer $\mathrm{MSeI}+\mathrm{C}$. Para o primer EcoRI + TA, náo houve amplificação. Bandas apresentando massa molecular acima de $300 \mathrm{pb}$ foram descartadas devido à resoluçáo ser insuficiente para discriminar as bandas.

Com base no dendrograma produzido a partir dos dados de AFLP (Figura 1) os isolados foram separados em dois grupos. O grupo I apresentou dois subgrupos, A e B. No 
subgrupo A estão inseridos os isolados EM1, EM2, EM4, EM6, PF24, IRB25, PF13, PF20, PF23, MF218, MF418, EM9 E PF22, no subgrupo B estão os isolados EM7, PF12, PF11 e IRB27. No grupo II estáo os isolados EM8, PF17 e MU28. A correlação cofenética apresentou valor de $r=0,99$. A similaridade genética variou de acordo com a procedência dos isolados, demonstrando uma variação intra-específica, onde isolados de mesma procedência foram distribuídos em diferentes grupos e subgrupos, evidenciando a variabilidade genética existente entre isolados provenientes da mesma localidade.

O coeficiente de variação genética entre os isolados foi de 0,0216 e a similaridade genética entre todos os indivíduos foi de $94,95 \%$, indicando que os isolados pertencem à mesma espécie, concordando com as observaçóes morfológicas. Diferente do observado por Freeman et al. (2000) que caracterizaram isolados de Colletrotrichum spp. causadores de antracnose em diferentes hospedeiras, usando caracteres morfológicos e marcadores moleculares, e observaram divergências entre os resultados obtidos para identificação das espécies, quando compararam dados morfológicos aos dados de marcadores moleculares. No estudo de Peres et al. (2003) que avaliaram a variabilidade morfocultural e genética por meio de marcadores AFLP, de fungos associados à podridão peduncular em mamoeiro (Carica papaya L.), incluindo C. gloeosporioides, evidenciou uma ampla variabilidade morfológica entre os isolados, não havendo relação entre as características morfológicas e as análises moleculares.

Quanto às observaçóes da procedência, os isolados provenientes de Presidente Figueiredo-AM apresentaram

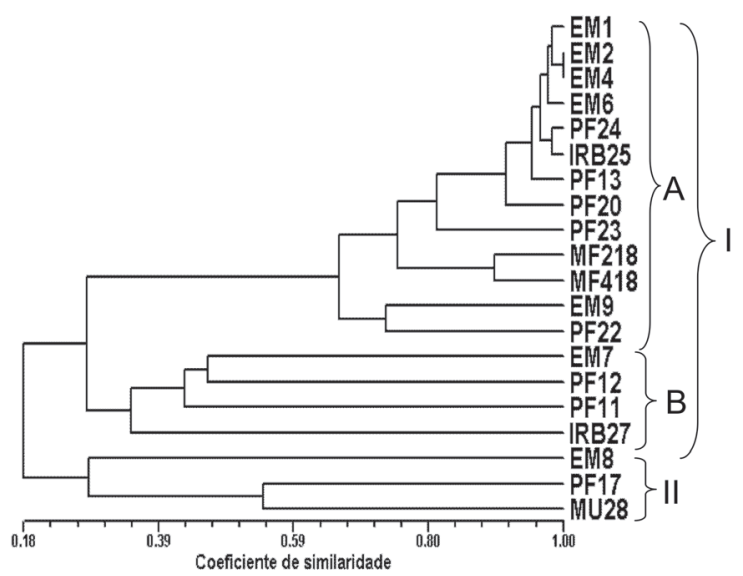

Figura 1- Dendrograma de similaridade genética de isolados de Colletotrichum guaranicola. Isolados EM1, EM2, EM4, EM6, EM7, EM8, e EM9 provenientes do campo experimental da EMBRAPA Amazônia Ocidental, Manaus-AM; PF11, PF12, PF13, PF17, PF20, PF22, PF23 e PF24 de Presidente Figueiredo-AM; IRB25 e IRB27 de Iranduba-AM; MU28 de Maués-AM; MF218 e MF418 da fazenda experimental da Universidade Federal do Amazonas, Manaus-AM. Os números em cada forquilha representam os valores de bootstrap.
85,6\% de locus polimórficos por loci, os do campo experimental da EMBRAPA Amazônia Ocidental-AM 79,80\%, indicando maior variabilidade genética entre os isolados provenientes destas localidades. Este resultado pode ser devido à maior quantidade de isolados analisados destas procedências, evidenciando maior número de loci polimórficos.

Para o município de Iranduba-AM, foram analisados dois isolados, que apresentaram 53,54\% de loci polimórficos, evidenciando a variabilidade genética entre isolados da mesma procedência mesmo entre poucos indivíduos. A menor variabilidade observada foi entre os isolados obtidos da Fazenda Experimental da UFAM - Manaus-AM, com 7,07\% de polimorfismo.

A variabilidade genética observada entre os isolados pode ser decorrente de diversos mecanismos geradores de variabilidade em fungos mitospóricos, como mutação e recombinação parassexual (Agrios 2005; Azevedo 2009) que podem ocorrer em condiçóes naturais. Levando em consideração que a antracnose é uma doença endêmica em áreas de cultivo de guaranazeiro no Amazonas, onde múltiplas infecçóes ocorrem constantemente resultando em alta taxa de reprodução do patógeno, o que favorece a ocorrência de variantes dentro da espécie.

Ainda são necessários estudos adicionais visando esclarecer a identidade taxonômica do agente causal da antracnose do guaranazeiro, comparando o mesmo com outras espécies dentro do gênero Colletotrichum, em virtude da fragilidade dos caracteres morfológicos utilizados para a descrição da espécie. De acordo com O’Neill et al. (1997) a técnica de AFLP pode facilitar a identificação de genes específicos associados com a especificidade por hospedeiro, virulência e avirulência, fornecendo subsídios para investigação de mecanismos geradores de variação genética em fungos.

\section{BIBLIOGRAFIA CITADA}

Agrios, G.N. 2005. Plant Pathology. 50 Ed. Elsevier Academic Press, Burlington -USA. 922 pp.

Albuquerque, F.C. 1961. Guarana anthracnose. Ministério da Agricultura/Serviço de Informação Agrícola: Rio de Janeiro. 22 pp. (in Portuguese)

Azevedo, J.L. 2009. Microorganisms Genetics. Editora UFG, GoiâniaGO. 536 pp. (in Portuguese).

Bentes, J.L.S.; Barreto, R.W. 2004. Taxonomic reevaluation of Colletotrichum guaranicola Albuq. causal agent of guaraná anthracnose. Acta Amazonica, 34: 129-131. (in Portuguese, with abstract in English).

Bentes, J.L.S.; Gasparotto, L. 1999. Pathogenicity of Colletotrichum guaranicola Albuq. isolates in clones of guarana (Paullinia cupana var. sorbilis). Fitopatologia Brasileira, 24: 267 (in Portuguese).

Creste, S.; Tulmann Neto, A.; Figueira, A. 2001. Detection of single sequence repeat polymorphisms in denaturing polyacrylamide 
Variabilidade genética de Colletotrichum guaranicola usando marcadores AFLP sequencing gels by silver staining. Plant Molecular Biology Reporter, 19: 299-306.

Cruz, C.D. 2006. Program Genes: multivariate analysis and simulation. UFV, Viçosa-MG. 175 pp. (in Portuguese).

Dini-Andreote, F.; Pietrobon, V.C.; Dini-Andreoti, F; Romão, A.S.; Spósito, M.B.; Araújo, W.L. 2009. Genetic variability of Brazilian isolates of Alternaria alternata detected by AFLP and RAPD techniques. Brazilian Journal of Microbiology, 40: 670-677.

Duarte, M.L.R.; Albuquerque, F.C.; Correa, M.P.F. 1995. Physiological and morphological changes in Colletrichum guaranicola isolates. Fitopatologa Brasileira, 20: 141-144. (in Portuguese).

Ferreira, M.E.; Grattapaglia, D. 1996. Introduction to use of molecular markers in genetic analysis. 2. ed. EMBRAPA, Cenargen, BrasíliaDF. 220 pp. (in Portuguese).

Freeman, S.; Katan, T.; Shabi, E. 1998. Characterization of Colletotrichum species responsible for anthracnose disease of various fruits. Plant Disease, 82: 596-605.

Jaccard, P. 1901. Comparative study of the floral distribuition in a portion of the Alps and the Jura. Bulletin of the Voudoise Society of Natural Sciences, 37: 547-579. (in French)

Mantel, N. 1967. The detection of disease clustering and a generalized regression approach. Cancer Research, 27: 209-220.

Menezes, M. 2002. Biological and taxonomic aspects of Colletotrichum species. Fitopatologia Brasileira, 27: 23-24 (in Portuguese).

O’Neill, N.R; van Berkum, P.; Lin, J.; Kuo, J.; Ude, G.N; Kenworthy, W.; Saunders, J. A. 1997. Application of amplified restriction fragment length polymorphism for genetic characterization of Colletotrichum pathogens of alfalfa. Host Genetics and Resistance, 87: 745-750.

Peres, A.P.; Silva-Mann, R.; Vieira, M.G.G.C.; Machado, J.C. 2003. Morfocultural variability and genetics of fungi associated with stalk rot of papaya. Ciência e Agrotecnologia, 27: 1053-1062 (in Portuguese, with abstract in English).

Raeder, U.; Broda, P. 1985. Rapid preparation of DNA from filamentous fungi. Letters in Applied Microbiology, 1: 17-20.

Rodrigues, L.M.R. 2010. Assessment of aggression and genetic characterization of strains of Ralstonia solanacearum isolated from different host plants. Dissertação de Mestrado, Universidade
Estadual Paulista, Botucatu, São Paulo. 68pp. (in Portuguese, with abstract in English).

Silva-Mann, R.; Vieira, M.G.G.C; Machado, J.C., Bernardino Filho, J.R.; Salgado, K.C.C.; Stevens, M.R. 2005. AFLP markers differentiate isolates of Colletotrichum gossypii from C. gossypii var. cephalosporioides. Fitopatologia Brasileira, 30: 169-172. (in English, with abstract in Portuguese).

Sneath, P.H.A; Sokal, R.R. 1973. Numerical Taxonomy: the principles and practice of numerical classification. W.H. Freemam, San Francisco, USA. 573 pp.

Sutton, B.C. 1980. The Coleomycetes. CABI Publishing, Surrey, England. 696 pp.

Sutton, B.C. 1992. The Genus Glomerella and it's anamorph Colletotrichum, p. 1-26. In: Bailey, J.A., Jeger, M.J. (Eds.) Colletotrichum: biology, pathology and control. CAB International, Wallinford, U.K.

Talhinhas, P.; Sreenivasaprasad, S.; Neves-Martins, J. Oliveira, H. 2002. Genetic and morphological characterization of Colletotrichum acutatum causing anthracnose of lupins. Phytopathology, 92: 986-996.

Tavares, A.M.; Atroch, A.L.; Nascimento Filho, F.J.; Pereira, J.C.R.; Araújo, J.C.A.; Moraes, L.A.C.; Santos, L.P.; Garcia, M.V.B.; Arruda, M.R.; Souza, N.R.; Anagelo. P.C.S. 2005. Culture of guaraná in the Amazon (4 Ed.) Sistemas de Produção 2. Embrapa Amazônia Ocidental, Manaus - AM. 40 pp. (in Portuguese).

Véras, S.M.; Gasparotto, L. E; Menezes, M. 1997. Physiomorphological variability of Colletotrichum guaranicola on different substrates. Arquivos de Biologia e Tecnologia, 40: $297-$ 305. (in Portuguese, with abstract in English).

Vos, P.R.; Hogers, M.; Bleeker, M.; Van De Lee Reijans, T.; Hornes, M.; Fritjers, A.; Pot, J.; Peleman, J.; Kuiper, M.; Zabeau, M. 1995. AFLP: A new concept for DNA fingerprinting. Nucleic Acids Research, 23:4407-4414.

Yeh, F.C.; Yang, R.C., Boyle, T. 1999. Microsoft Windown bases freeware for population genetic analysis. POPGGEN. Release 1.31. Edmonton, Univesity of Alberta.

Recebido em 10/02/2010

Aceito em 12/09/2010 
